\title{
Adding New Vocabulary While Playing Casual Games: Young People in Brunei as a Case Study
}

\author{
Juraidah Musa \\ Sultan Hassanal Bolkiah Institute of Education (SHBIE), \\ Universiti Brunei Darussalam \\ Jalan Tungku Link, BE 1410, Brunei Darussalam \\ Tel: +673-8973897Ｅ-mail: juraidah.musa@ubd.edu.bn
}

Received: July 20, 2014 Accepted: October 25, 2014 Published: February 1, 2015

doi:10.5296/jmr.v7i2.6939 URL: http://dx.doi.org/10.5296/jmr.v7i2.6939

\begin{abstract}
Playing casual games has become a popular activity for young people. One main reason is casual games can be played everywhere using smart phones or tablets. The easy accessibility has made casual game the most playable video game during leisure time. Although playing casual games is a leisure activity, without knowing, young people have developed a new group of vocabulary. Drawing upon data from observations and think-aloud techniques, this paper presents the findings of how young people develop new vocabulary while playing casual games.
\end{abstract}

Keywords: Casual Games, Vocabulary, Young People, Gameplay experiences, Think-aloud technique 


\section{Introduction}

The amount of time young people spend on playing video games is getting higher. According to a survey done by Kaiser Family Foundation (Rideout, Foehr, \& Roberts, 2010), within 10 years there has been a substantial increase in the amount of time spent by young people playing video games. With the emerging of new type of video game, called casual game (Juul, 2010), young people now can play games anytime and anywhere. Features such as easy to play and easy accessibility (Juul, 2010; Kuittinen, Kultima, Niemelä, \& Paavilainen, 2007) make causal game as one emerging type of video games that have been played by young people. If we look around us, we can see that young generation have been exposed to casual gameplay activities. With the exposure to these activities, it is worth to know whether casual games can help young people in the acquisition of new vocabulary.

This study is influenced by Gee's learning principles of video games. Gee (2003) lists 36 learning principles, in which he organises them into 3 sections called Empowered Learner (players are taking responsibility in designing and creating the virtual world of video game), Problem Solving (players are able and eager to solve the problems in video game due to the well-order from easy to complex problems) and Understanding (players are able to understand the "whole concept of the video game" through experience on playing them") $(2005$, p. 4). One of his learning principles under the section "understand" is that players can learn to participate in "semiotic domains" made up of signs and symbols, which include digital artifacts of text, images, sound and characters used to create meaning. Players can learn digital artifacts, words and symbols that have meanings that are specific to a particular set of domains and contexts. Therefore, it is important to know to what extent the digital artifact of text presents in a game environment can help young people in acquisition of new vocabulary. Some research studies had investigated the acquisition of vocabulary while playing video game. Recent gaming studies such as (Chen \& Yang, 2013; Ranalli, 2008) state that video games can help students in the acquisition of new words. They claim that participants in their study have significantly improved their vocabulary knowledge while playing video games. How about when young people play casual games? To expand our knowledge on the acquisition of vocabulary with different type of video games, this study is conducted to investigate on how playing casual game can help players in the acquisition of new words.

\subsection{Gameplay activity and Language Learning}

Game scholars as (Gee, 2007; Prensky, 2004; Shaffer, 2006) argue that gameplay activity can be powerful activities for education. Playing video games are definitely not a waste of time (Gee, 2003), for whenever one plays a game, and whatever game one plays, learning happens constantly, whether the players want it to, and are aware of it, or not (Prensky, 2004). Their works on video games and education has attracted many researchers (such as Squire, 2004) to investigate the benefits of gameplay activities on different subject area such as Geography and History.

In term of language learning, Gee (2007) states that video games are surrounded by written texts. It could be in terms of instructions, hints on how to solve the game and brief 
introduction of characters. This rich text environment has allowed researchers to study the potential of video game in language learning. In regards with the acquisition of vocabulary, several research studies have investigated the benefits of gameplay activities on this matter. Some recent studies have shown that video game provide new vocabulary lists to players. Chen and Yang (2013) utilized a video game called Bone to investigate on how this adventure video game enhance English listening, reading, vocabulary skill of a group of college students in Taiwan. In terms of vocabulary skill, their findings indicate that the college students gained some new words after playing Bone. Similar to a research study conducted by Ranalli (2008) on nine university students who English Language is not their first language. Based on the study, he found that a simulation game called The Sims had statistically significant improvements in the participants' vocabulary knowledge.

\subsection{What is Casual Game?}

Casual games is a common term used by gaming industries (Juul, 2010), which referring to simple, easy and accessible type of video games that can be played on most portable technologies, such as smart mobile phones and tablets. With its casual features, this type of game can be played in everyday practices. Casual games are purposely designed for all individuals. This has mentioned by Casual Game Associate (CGA), in which casual games are developed for the general public and families. The games are platform agnostic, meaning they can be played via the Internet, PC and Macintosh computers, Xbox, PlayStation, Nintendo DS, Wii and even mobile phones and PDA. They are nonviolent, arcade-style games that involve puzzles, words, board and card games, game show and trivia (excerpt from http://www.casualgamesassociation.org).

Nowadays casual games are the most popular categories of games played over the Internet. According to a games market researcher called Newzoo (Feb, 2012), an amazing 76\% (Europe) to $93 \%$ (Asia) of all gamers play casual games. Recent study made by Entertainment Software Association (ECA) states that casual game is the type of online game that have been played most often (2014). The popularity of casual gaming is due to the features of casual games that are quick to access, easy to learn and require no previous special video game skills, expertise or regular time commitment to play (Amsterdam \& Cheng, 2011). Since casual games are the most popular categories of games played in recent years Newzoo (Feb, 2012), it is an opportunity to fully exploit the advantageous features of casual game and its positive impact to learning processes (Gee, 2007) to serve the acquisition of new vocabulary of young people.

\subsection{Features of Casual Game}

Casual gaming is the new revolution of video games. According to Juul (2010), to consider a video game a casual game, he listed five components of casual gaming (p 50). Firstly, Fiction - Casual games are generally set in pleasant environments. Casual game design has emotionally positive fictions as opposed to the emotionally positive fiction and the emotionally negative, vampires and war settings of traditional video games. Second component is usability - The player trying to play the game may or may not have trouble understanding how to play. Casual games presuppose little knowledge of video game 
conventions. The next component is Interruptibility - Casual game design is very interruptible. A game design demands a certain time commitment from the player. It is not that casual games can only be played for a short periods of time, but that casual game design allows the player to play a game in brief bursts. The fourth component is about punishment and challenges. A game challenges and punishes the player for failing. Casual games often become very difficult during the playing of a game, but they do not force the player to replay large parts of the game. Single-player casual game design has lenient punishments for failing. And the final one is juiciness (excessive positive feedback) - Though this was not predicted by the descriptions of casual players, casual game design commonly features excessive positive feedback for every successful action the player performs.

\section{Research Questions}

This study aims to investigate on how casual gameplay activities can help introducing new vocabulary to players. Based on this aim, the research question is generated as follows:

RQ1: How does the casual gameplay activity help in the acquisition of new vocabulary?

RQ2: What type of vocabulary may be given by the casual gameplay activity?

\section{Research method}

In order to answer the research questions mentioned above, this study employed a case study research approach with observations and think-aloud technique as methods for collecting data.

\subsection{Participants}

Twenty students aged between 10 and 12 were recruited from four primary and secondary schools in Brunei to participate in this research study. In selecting the participants, students attending the after-school club are the convenience sampling (Marshall, 1996) for this study, since this study utilised the school computer clubroom as a site to carry out the data collection processes. It is very convenient for the researcher in terms of time and effort.

Participants included eleven frequent players and nine infrequent players. Initially, before collecting data, all potential participants were asked to complete a brief questionnaire to identify their play activity with casual games. Based on their answer to the questionnaire "How many times a week do you play casual games?" The frequent players can be defined as participants who play casual games every day, while infrequent players play casual game during weekends and non-school day.

\subsection{Materials}

In order to investigate the casual gameplay acitvities, iPad was used as a platform for participants to play casual games. Two casual games titled as Candy Crush (King.com) and Minecraft (Mojang) were installed beforehand. However, participants were allowed to bring their own device with these games installed earlier. Two games used in this study were selected due to its popularity and its suitability for young people in this study. 


\subsection{Procedure}

The data collection process is a one to one method. It means that only one participant to be observed at one time. This method allowed the researcher to concentrate the gameplay activity for each participant. The observation process for each participant took place for thirty minutes. The first thirty minutes has been decided the best time for obtaining quality data. During those 30 minutes, the participants played any casual games that installed on the iPad. While playing casual game, the participants were asked to say out loud whenever they found any words that they never knew or understood. This process was called a think-aloud technique (Ericsson \& Simon, 1985). However, for the purpose of this study, rather than asking the participants do the think-aloud technique by themselves, they were guided by questions, which asked by the researcher. By asking questions, the researcher was able to access the cognitive processes of the participant. Such questions were: Do you know this term? Can you explain to me the meaning of this term? All observation processes were video recorded.

\subsection{Data Analyses}

All data were transcribed using HyperResearch. Video data were segmented into a 30 -seconds period to make it easier for further analysing. This study employed the content analysis process in which it is systematically work through each transcript; looking to see how often the factor arise (Harding, 2013). All video segments were selected based on the activity that have potential on generating the acquisition of vocabulary. If the particular activity has the vocabulary acquisition process, the researcher will extract the activity for further interpretation.

\section{Results and Discussion}

\subsection{Acquisition of vocabulary}

In regards with the acquisition of new vocabulary while playing casual game, all participants in this study showed that they have added new words in their own dictionary. This finding confirmed the studies by Chen and Yang (2013) and Ranalli (2008), in which they also stated that players gained their vocabulary by playing video game. However, this present study indicates that all participants do not know the actual meaning of these new emergent words. Guided by a question from the researcher, they just interpreted the word based on the theme of the casual game. Below are the two examples on how participants gained new vocabulary from playing casual games and how they interpreted the new words.

Researcher: Do you know what Ingredients is?

Anna: No (long pause) but I know... ingredients (different pronunciation) is this one (pointing a cherry)

Researcher: Have you heard Ingredients before?

Anna: No...I do not recall

(10, play Candy Crush (King.com)) 
The above quote is a conversation from one of the infrequent players who played level 11 of Candy Crush (King.com) (King.com) during the data collection process. In this level, the goal is to bring all ingredients down to the bottom. The ingredient is one cherry that needs to bring down. Conversations shown above indicates that the participant knew the term ingredients exists. Although he ignored the actual meaning of ingredients, nevertheless he was able to connect the term ingredients with cherry.

Researcher: How about building terrain? Do you know that term?

Ali: I know building but I don't know terrain

Researcher: Can you relate terrain with your gaming now?

Ali: mmm...now I am building my own world...then terrain is a world....

(12, play Minecraft (Mojang))

The above quote is a conversation from one of the frequent players who played Minecraft (Mojang): pocket edition (Mojang). The objective of Minecraft (Mojang) is to build virtual realities in a $3 \mathrm{D}$ procedurally generated world. From the conversation, it can be seen that this participant has gained his vocabulary by knowing a new term terrain, which he encountered during the casual gameplay activities. It also shows that this player has interpreted the term terrain with his gameplay activity - build a virtual world, even though he was unaware the actual meaning of terrain.

Participants ignored the meaning of the actual term but they know that term in a situated meaning. The finding on the interpretation of players to the new words is what Gee (2003) states as Situated Meaning Principles, in which the meanings of signs such as words, text and symbols are situated in embodied experience. However, although they are situated in meaning, Gee (2003) argues that they can be good precursor for learning, because mastering a particular domain facilitates learning in another domain. For this transfer to one domain to another domain can be recommended for further research.

\subsection{The Encounter of New Vocabulary}

Another finding is the way on how they gained the vocabulary. This study indicated that the young people realised the words when they have direct interaction with the word. The direction interaction with the words means that the word must have some connections to solve the game. If the word is purposely for labelling, they just ignored it. As shown below, this is an example on how player ignore the some words in Candy Crush (King.com).

Researcher: Do you notice the term glazed grove?

Amin: No.

Researcher: This one (pointing to the word)

Amin: (Shaking his head)

(10, Candy Crush (King.com)) 


\section{Mll Macrothink}

The above conversation shows that this participant did not realise the word glazed grove while playing Candy Crush (King.com). This may be because the purpose of this word is only for labelling a world that presents in Candy Crush (King.com), which has no direct interactions with the player. All participants showed a similar behaviour when it comes to the words that do not have any purpose to solve the game.

It shown that they acted upon the word such as instructions for each level in Candy Crush (King.com). In Candy Crush (King.com), each level has different goal and player has to act upon it. In order to complete the goal of each level, player has to read and understand the instruction well. From this activity, the player is in the process of acquisition of new vocabulary. In this study, using think-aloud technique, participants were asked whether they understand the instruction, which lead to the enquiry of difficult words.

\subsection{Type of Vocabulary}

This study indicated that there is two group of vocabulary that players may obtain while playing casual games. Table 1 shows these two groups of vocabulary. General meaning is the group of vocabulary that found outside the virtual game environment. These words are purposely for managing the casual game such as synchronising to Facebook and changing graphic view. The other group is a vocabulary with situated meaning, in which this group of vocabulary is connected to the gameplay activity to solve the game.

\subsection{List of Vocabulary}

Table 1 shows the new vocabulary that obtained by participants in this study.

Table 1. List of Vocabulary Gained While Playing Casual Games: Candy Crush (King.com) and Minecraft (Mojang)

\begin{tabular}{|c|c|c|}
\hline Casual Games & $\begin{array}{c}\text { New Vocabulary } \\
\text { (General meaning) }\end{array}$ & $\begin{array}{c}\text { New vocabulary } \\
\text { (Situated-meaning) }\end{array}$ \\
\hline $\begin{array}{c}\text { Candy Crush } \\
\text { (King.com) }\end{array}$ & $\begin{array}{c}\text { Nynchronise, } \\
\text { Notifications, } \\
\text { Privacy }\end{array}$ & $\begin{array}{c}\text { Kingdom, Boosters, } \\
\text { Ingredients, Jackpot } \\
\text { Combos }\end{array}$ \\
\hline Minecraft & Server, Graphics & Cobblestone, Planks, \\
(Mojang) & & Torch, Spawn \\
\hline
\end{tabular}

\section{Conclusions}

This paper investigated on how playing casual game may helped young people in the acquisition of new vocabulary. Using a case study approach, this study produced several interesting findings that relate to the acquisition of new vocabulary. This study indicated that players of casual games may developed new group of vocabulary while playing casual game. 


\section{Macrothink}

Journal of Management Research

ISSN 1941-899X

2015, Vol. 7, No. 2

The vocabulary gains will happens if the words present in the casual game have direct interactions with the player, which is relevant and useful in solving the games. Another finding is the type of vocabulary found in Candy Crush (King.com) and Minecraft (Mojang). There are two groups of vocabulary; General meaning in which the words relates with managing activity of casual games and Situated meaning which relates to words that associates with the gameplay activities, that will help to solve the game. These research findings suggest for further exploration into to what extent such vocabulary gained through playing casual games can be transferred to other experiences.

\section{References}

Amsterdam, V., \& Cheng, K. (2011). Casual gaming. VU Amsterdam.

Chen, H.-J. H., \& Yang, T.-Y. C. (2013). The impact of adventure video games on foreign language learning and the perceptions of learners. Interactive Learning Environments, 21(2), 129-141. http://dx.doi.org/10.1080/10494820.2012.705851

Ericsson, K. A., \& Simon, H. A. (1985). Protocol analysis: MIT press.

Gee, J. P. (2003). What video games have to teach us about learning and literacy. Computers in Entertainment (CIE), 1(1), 20-20. http://dx.doi.org/10.1145/950566.950595

Gee, J. P. (2007). What video games have to teach us about literacy and learning: Revised and Updated Edition.

Harding, J. (2013). Qualitative data analysis from start to finish. London: SAGE.

Juul, J. (2010). A casual revolution: reinventing video games and their players. Cambridge, Mass.: MIT Press.

Kuittinen, J., Kultima, A., Niemelä, J., \& Paavilainen, J. (2007). Casual games discussion. Paper presented at the Proceedings of the 2007 conference on Future Play. http://dx.doi.org/10.1145/1328202.1328221

Prensky, M. (2004). What kids learn that's positive from playing video games: Simon Fraser University, Surrey Campus Library.

Ranalli, J. (2008). Learning English with The Sims: exploiting authentic computer simulation games for L2 learning. Computer Assisted Language Learning, 21(5), 441-455. http://dx.doi.org/10.1080/09588220802447859

Rideout, V. J., Foehr, U. G., \& Roberts, D. F. (2010). Generation M [superscript 2]: Media in the Lives of 8-to 18-Year-Olds. Henry J. Kaiser Family Foundation.

Shaffer, D. W. (2006). How computer games help children learn. Macmillan. http://dx.doi.org/10.1057/9780230601994

Squire, K. (2004). Replaying history: Learning world history through playing Civilization III. $(\mathrm{PhD})$, Indiana University Bloomington. 
Game Developer

Developer Candy Crush - King.com https://king.com/

Developer Minecraft - Mojang https://mojang.com/

\section{Copyright Disclaimer}

Copyright for this article is retained by the author(s), with first publication rights granted to the journal.

This is an open-access article distributed under the terms and conditions of the Creative Commons Attribution license (http://creativecommons.org/licenses/by/3.0/). 